\title{
EDITORIAL
}

\section{Adults with Congenital Heart Disease: At Long Last, Guidelines for Arrhythmia Management}

\author{
PETER P. KARPAWICH, M.Sc., M.D. \\ From the Section of Pediatric Cardiology, Carmen and Ann Adams Department of Pediatrics, The Children's \\ Hospital of Michigan, Wayne State University School of Medicine, Detroit, Michigan
}

Beginning with the first successful surgical closure of a patent ductus arteriosus in 1938, to open heart repair of septal defects in 1955 and into the current era, children born with potentially fatal congenital heart defects are now surviving and attaining adulthood in numbers not previously envisioned. The concept of "long term" survival, originally meaning 10 years postrepair, has been superseded by survival beyond 20 and even 40 years. At the current time, population estimates indicate that there are now nearly 3 million adults with congenital heart disease (ACHD) in the United States, Canada, and Europe; and that number is growing. Since a "repaired" congenital heart does not imply "normal," most of these patients will experience some complications, requiring lifelong medical care (Fig. 1). Prominent among these complications are arrhythmias that contribute to impaired quality of life, morbidity, and mortality. And although expert consensus guidelines dealing with various aspects of arrhythmia identification and patient management have been published since the 1980s, dealing primarily with ischemic heart disease, none fully apply to this growing ACHD population.

At the recent 35th Scientific Sessions of the Heart Rhythm Society, the Pediatric and Congenital Electrophysiology Society (PACES) presented the first-ever expert consensus arrhythmia management guidelines that focus specifically on the ACHD patient, taking into consideration specific cardiac anatomies, surgical repairs, and their sequelae, including heart failure. ${ }^{1}$ The 22 member, multidisciplinary and international writing committee included representatives from, and the publication was endorsed by, the American College of Cardiology, American Heart Association, Heart Rhythm Society, European Heart Rhythm Association, Canadian Heart Rhythm

Conflict of Interest: None.

Address for reprints: Peter P. Karpawich, M.Sc., M.D., Cardiac Electrophysiology Services, Section of Cardiology, The Children's Hospital of Michigan, 3901 Beaubien Blvd, Detroit, MI 48201. Fax: 313-993-0894; e-mail: pkarpawi@dmc.org

Received June 4, 2014; accepted June 4, 2014.
Society, and the International Society for Adult Congenital Heart Disease. It was a momentous task and all involved are to be congratulated on their efforts. Obviously, this is a work in progress and updated versions can be anticipated in the future as more information is gained on aging ACHD patients and their unique clinical presentations and management issues.

Nevertheless, these guidelines are recommended for any physician or healthcare provider currently caring for, or who intends to care for, these unique patients.

Compared with previous comparable publications, this PACES/HRS Expert Consensus Statement goes beyond just tabulating categories for management. As indicated in the Introduction, the purpose is to provide a basis of understanding of the scope of the problem and how to define optimal healthcare delivery, based as much as possible on published evidence. This is substantiated by an excellent list of over 600 references dealing with all aspects of ACHD. Presented topics include how best to evaluate the symptomatic as well asymptomatic ACHD patient including when to perform intracardiac electrophysiology studies. Discussed therapy deliveries include choosing the best pharmacologic treatments based on type of arrhythmia and anatomy, use of thromboprophylaxis, catheter-based ablation interventions, implantable cardiac devices (brady- as well as antitachycardia pacemakers and implantable cardiac defibrillators), resynchronization pacing for heart failure, as well as surgical options.

With an estimated $>90 \%$ survival to adulthood following surgical repair, children born with congenital heart disease are transitioning rapidly from the Pediatrician to Internist for primary health care. The recent addition of a subboard examination in Adult Congenital Heart sponsored by the American Board of Internal Medicine attests to the need for physicians trained to deal with this new patient subset. The PACES/HRS Expert Consensus Statement is a step in the right direction to assure updated information is available to optimize health-care delivery.

PACES/HRS Expert Consensus Statement on the Recognition and Management of Arrhythmias in Adult Congenital Heart Disease. 


\section{KARPAWICH}

A

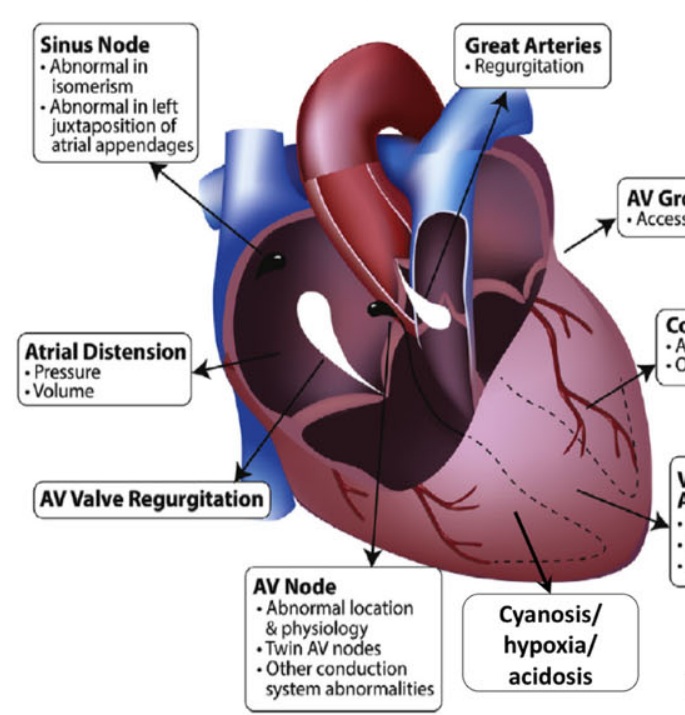

B

Post-operative

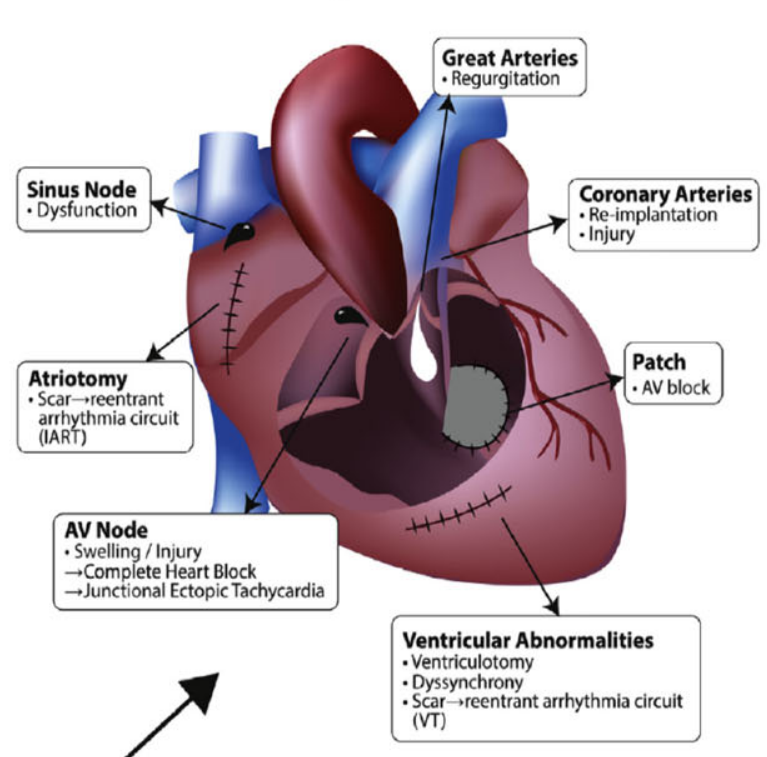

Medications

Electrolyte Disturbances

Repolarization Abnormalities

Systemic Illness

Inflammation

Figure 1. From the Consensus Guidelines, this schematic represents pre- and postoperative cardiac issues associated with congenital heart disease.

\section{Reference}

1. Khairy P, Van Hare GF, Balaji S, Berul CI, Cecchin F, Cohen MI, Daniels CJ, et al. PACES/HRS expert consensus statement on the recognition and management of

arrhythmias in adult congenital heart diseaseHeart Rhythm 2014 (in press; doi: 10.1016/j.hrthm.2014.05.009. [Epub ahead of print]). 